\title{
A Novel Method of Analyzing a Reaction Using the Data from Particle and Gamma-ray Detectors
}

\author{
Ilker Can Celik ${ }^{1 *}$ \\ 1* Harran University, Faculty of Art and Science, Departmant of Physics, Sanliurfa, Turkey, (ORCID: 0000-0002-2320-6584), ilkercan0066@harran.edu.tr
}

(1st International Conference on Applied Engineering and Natural Sciences ICAENS 2021, November 1-3, 2021)

(DOI: 10.31590/ejosat.997947)

ATIF/REFERENCE: Celik, I. C. (2021). A Novel Method of Analyzing a Reaction Using the Data from Particle and Gamma-ray Detectors. European Journal of Science and Technology, (28), 280-284.

\begin{abstract}
The radioactive isotope beam (RIB) of ${ }^{25} \mathrm{Na}$ at $5 \mathrm{MeV} / \mathrm{u}$ energy in maximum $3 \times 10^{7} \mathrm{pps}$ intensity was fired on a deuterated polyethylene $\left(\mathrm{CD}_{2}\right)$ to investigate mainly (d,p gamma) reaction. However, there were other reaction possibilities, which were arisen from the same collision, to be eliminated wisely. As to a particle detector and a gamma-ray detector, highly selective double-sided silicon strip detectors (DSSSD) and high purity germanium detectors (HPGe) were employed to make delicate selections of distinctive energies of experimentally populated excited states of ${ }^{26} \mathrm{Na}$. The motivation of this work was to show how to combine the information coming out of two different types of detectors in terms of energies to reach out a new unobserved data. This study was a part of the experiment with Silicon Highly-segmented Array for Reactions of Coulex (SHARC) and TRIUMF-ISAC Gamma-ray Escape-Suppressed Spectrometry (TIGRESS) in Canada.
\end{abstract}

Keywords: RIB, SHARC, TIGRESS, ${ }^{26} \mathrm{Na}$, reaction

\section{Parçacık ve Gama Işını Dedektörlerini Kullanarak Bir Reaksiyonu Analiz Etmenin Farklı Bir Yöntemi}

Öz

${ }^{25} \mathrm{Na}$ içeren radyoaktif izotop 1 şını, $5 \mathrm{MeV} / \mathrm{akb}$ enerjide ve maksimum saniyede $3 \times 10^{7}$ parçacık içerecek şekilde deuterated polyethylene $\left(\mathrm{CD}_{2}\right)$ hedef üzerine (d,p gama) reaksiyonunu araştırmak üzere gönderilmiş̧ir. Buna rağmen, aynı çarpışmadan kaynaklanan farklı reaksiyon türleri olabileceği için, bunların dikkatlice ayrıştırılması gereklidir. Parçacık ve gama ışını dedektörü olarak, çift taraflı şeridi olan silikon dedektörleri ve yüksek saflıkta germenyum dedektörleri kullanılarak, ${ }^{26} \mathrm{Na}$ çekirdeğinin farklı enerjilerdeki durumları elde edilmiştir. Bu çalışmanın motivasyonu ise, farklı tipteki detektörlerden gelen bilgileri birleştirerek, daha önceden gözlenmemiş yeni verilere nasıl ulaşılabileceğini göstermekdi. Bu çalışma, SHARC ve TIGRESS dedektörlerinin bulunduğu Kanada'da yapılan deneyin bir parçasıdır.

Anahtar Kelimeler: Radyoaktif izotop ışını, SHARC, TIGRESS, ${ }^{26} \mathrm{Na}$, reaksiyon.

\footnotetext{
* Corresponding Author: ilkercan0066@harran.edu.tr
} 


\section{Introduction}

In this work, the ${ }^{26} \mathrm{Na}$ was populated by neutron transfer reaction of ${ }^{25} \mathrm{Na}(\mathrm{d}, \mathrm{p} \gamma)$; however, it had been produced before in many forms of other reactions. Not all, but some reported reaction types were in the structure of ${ }^{26} \mathrm{Ne}(\beta$-decay) (Weissman, 2004), ${ }^{26} \mathrm{Mg}\left(\mathrm{t},{ }^{3} \mathrm{He}\right)\left(\right.$ Flynn \& Garret, 1974), ${ }^{26} \mathrm{Mg}\left({ }^{11} \mathrm{~B},{ }^{11} \mathrm{C}\right)($ Scott at al, 1974), ${ }^{14} \mathrm{C}\left({ }^{14} \mathrm{C}, \mathrm{d} \gamma\right)\left(\right.$ Lee at al., 2016), ${ }^{26} \mathrm{Ne}(\mathrm{d}, 2 \mathrm{n} \gamma)$ (Obertelli at al., 2006), ${ }^{26} \mathrm{Mg}(\mathrm{n}, \mathrm{p})$ (AIP Conference Proceedings, 1986), and ${ }^{26} \mathrm{Mg}\left({ }^{7} \mathrm{Li},{ }^{7} \mathrm{Be}\right)$ (Ball at al., 1972). All these reactions have

something in common. Both particles and $\gamma$-rays played an imported role in these reactions. They helped to populate and to depopulate a specific nucleus in different energies. This was one way to dissipate their residual excitation energy $\left(\mathrm{E}_{\mathrm{ex}}\right)$. Therefore, not just the information of a particle data but also the $\gamma$-ray outcomes should be analyzed depending on the reaction. The participation of both helps to confirm the certain state of a nucleus in different perspectives. Also, the detected particle type gives a clue on the reaction type.

\section{Materials and Methods}

In this study, the beam of ${ }^{25} \mathrm{Na}$ was impinged on $\mathrm{CD}_{2}$ target as a compound. In Fig. 1a, it was clear that the target didn't include solely Carbon and Deuterium, but it was contaminated with Hydrogen atom as well. To investigate what happened in the reaction, some theoretical lines overlapped with the data from scattered proton kinetic energy as seen in the Fig. 1a. Another aspect to notice on the Fig. 1a was the gaps in angle coverage below $36^{\circ}$, in the range of $82^{\circ}-95^{\circ}, 142^{\circ}-147^{\circ}$, and above $173^{\circ}$ for the full coverage from $0^{\circ}$ to $180^{\circ}$ in $\theta$ angle. Meanwhile, more details of the experiment and particle detector-set of SHARC (Celik, 2014; Wilson, 2012) and $\gamma$-ray detector clovers of TIGRESS (Celik, 2014; Wilson, 2012) can be found elsewhere. If the solid angle plots in Fig. 1b and 1c were also checked for the SHARC as used in the experiment, the reason of the gaps within some angles will be understood in a relation with the coverage of the particle detectors. Note that, this simulated solid angle calculations included broken strips during the detector as well.
Therefore, the angle match between Fig. 1a and 1b was selfexplanatory. By knowing the reaction mechanism and details such as angle coverage, the number of particle detectors in need can be compensated due to the experiment budget as in the current study.

For instance, the number of detectors in upstream were more because the reaction of interest $(d, p \gamma)$ occurred mostly in upstream side of the detector set-up. In addition, each double sided silicon stripped detector (DSSSD) had 48 back strips along the beam's direction as $\theta$ angle and 24 front strips along the circular \varphi angle which was around the DSSSD detectors. By having more strips along the beam direction rather than in $\varphi$ angle, the aim was to maximize the angle coverage in the angle of the interest as seen in Fig. 1a. Additionally, the solid angle histogram helped to calculate the total detected particle counts. It was done by dividing detected particle-counts histogram into solid angle histogram within the same $\theta$ angle coverage from $0^{\circ}$ to $180^{\circ}$. Another point to notice in Fig. 1a was that the theoretical $(d, p)$ reaction lines lowered themselves as the excited energy increased. The populated energy of $5.38 \mathrm{MeV}$, for example, was the lowest slope among the other $(\mathrm{d}, \mathrm{p})$ lines due to the minimum detectable (threshold) proton energy. Lastly, the Fig. 1 could give the details of a possible angle gate information in the analysis depending on the detector's location. It was crucial to use beneficial gates in the analysis to filter the data.

Figure $2 \mathrm{a}$ shows the excitation energies as retrieved by the proton energy as detected by the SHARC detector versus the corresponding $\gamma$-ray energies as detected by the TIGRESS clovers. Besides, Fig. $2 \mathrm{~b}$ indicates the possible explanation of seeing states above neutron threshold energy of ${ }^{26} \mathrm{Na}$. After the ${ }^{25} \mathrm{Na}(\mathrm{d}, \mathrm{p} \gamma){ }^{26} \mathrm{Na}$ reaction, ${ }^{26} \mathrm{Na}$ can emit a neutron to dissipate its surplus energy above the threshold. At that moment, there is a chance that excited states of ${ }^{25} \mathrm{Na}$ might be created. Since the 2D plot was constructed by the scattered proton energy, we might reach higher energies by adding the neutron separation energy of $5.574 \mathrm{MeV}$ on the top of $\left(\mathrm{d}, \mathrm{d}^{\prime}\right)$ inelastic scattering energies as shown in Fig. 2b. From Fig. 1a, it was known that (d,d') inelastic scattering event was existed. Finally, we can get the corresponding $(\mathrm{d}, \mathrm{p})$ inelastic scattering energies before neutron was departed from $26 \mathrm{Na}$ as shown in the level scheme in Fig. $2 \mathrm{~b}$

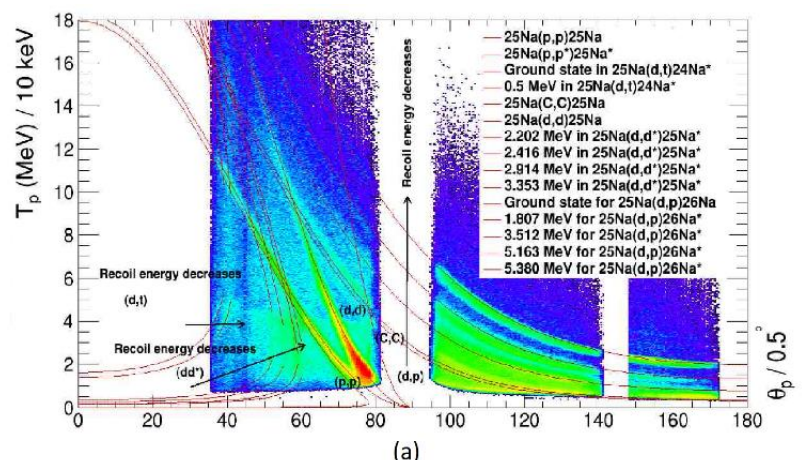

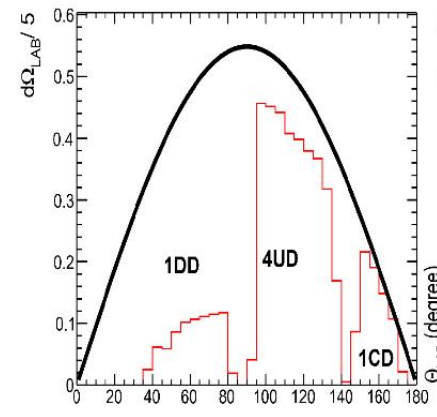

(b)

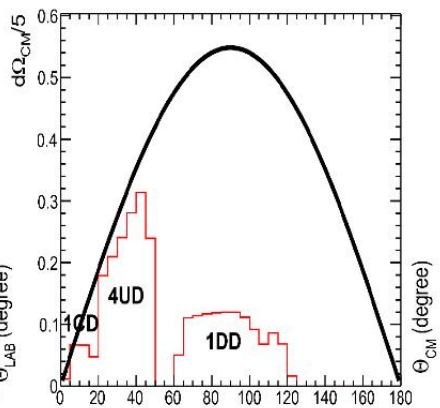

(c)

Figure 1: From the scattered and detected proton kinetic energies, re-evaluated excitation energies for various possible reaction scenarios were overlapped with the experimental data in ${ }^{25} \mathrm{Na}(\mathrm{d}, \mathrm{p} \gamma)^{26} \mathrm{Na}$ in Fig. 1a. Additionally, Fig. 1b in laboratory frame (LAB) and Fig. 1c in centre of mass frame (CM) indicates the calculated solid angle coverage of the SHARC detector. Full coverage of solid

line on figure $\mathrm{b}$ and $\mathrm{c}$ was fitted by the function of $\mathrm{d} \Omega=\sin (\theta) d \theta d \varphi$. Whilst $1 \mathrm{DD}$ and $1 \mathrm{CD}$ stands for 1 downstream and $1 \mathrm{CD}$ detector, 4UD represents 4 upstream detectors. 


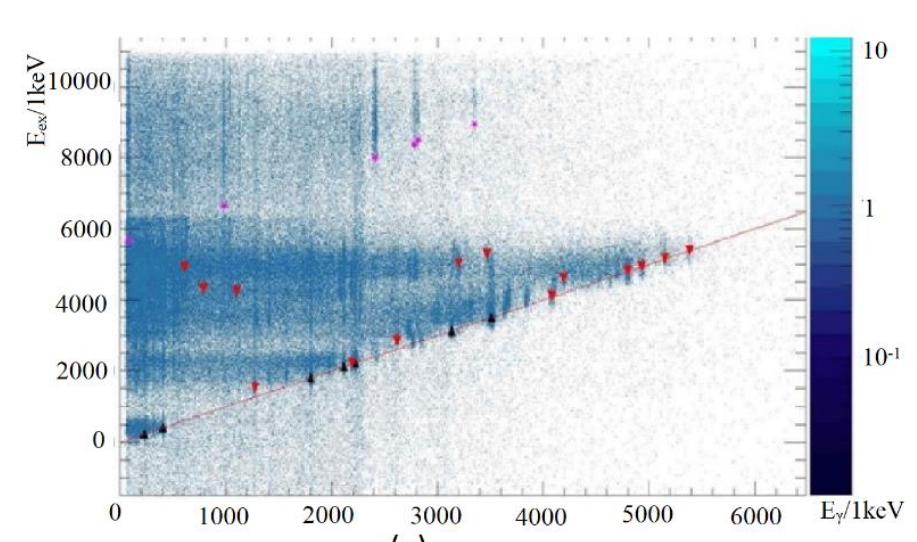

(a)

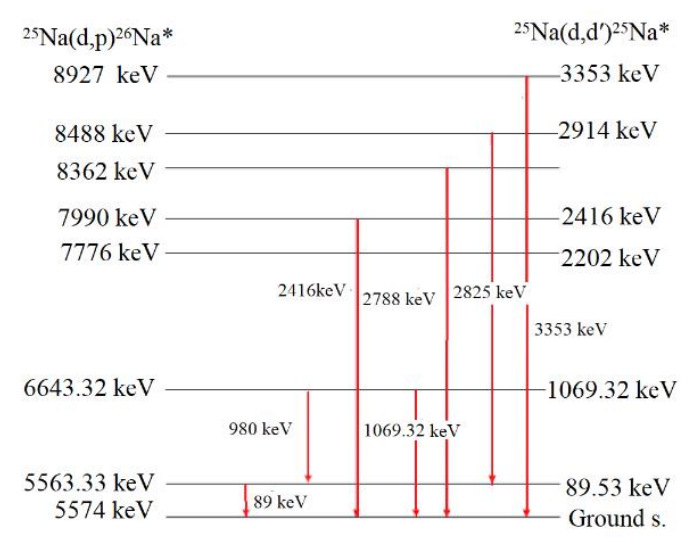

(b)

Figure 2: On the left figure, these color-coded dots show previously analyzed (Wilson, 2012) and updated version (Celik, 2014) of the analysis. Six purple dots above $5.574 \mathrm{MeV}$ show neutron separation energy threshold of ${ }^{26} \mathrm{Na}$, so they don't represent $(\mathrm{d}, \mathrm{p})$ transfer reaction. Whilst the states to transfer directly to the ground state of ${ }^{26} \mathrm{Na}$ lie along the diagonal, other states with $\gamma$-ray cascades stay above the red line. On the right side, $\gamma$-ray level scheme of ${ }^{26} \mathrm{Na}$ and ${ }^{25} \mathrm{Na}$ was provided for a comparison (Celik, 2014; Krämer at al., 1971; Jänecke, 1973; Firestone, 2009 ).


Figure 3: TRIFOIL was a zero-degree photomultiplier detector to reduce the noise and to select beam-like particles. Details can be found elsewhere (Wilson, 2012). Fig a shows $\mathrm{E}_{\mathrm{ex}}$ spectrum of ${ }^{25} \mathrm{Na}$ in red and ${ }^{26} \mathrm{Na}$ in black. Detected deuteron kinetic energy versus its scattered $\theta$ angle is shown with some overlapping state energy lines. Corresponding $E_{\text {ex }}$ energy of a $\gamma$-ray at $2416 \mathrm{keV}$ was shown in $(\mathrm{d}, \mathrm{p})$ and $(\mathrm{d}, \mathrm{d})$ related spectra in Fig. $\mathrm{c}$ and $\mathrm{d}$ here. Details this analysis can be found elsewhere (Celik, 2014).

The selectivity of the reaction can be proven to run the data as if there was a $\left(\mathrm{d}, \mathrm{d}^{\prime}\right)$ interaction as shown in Fig. 3. Excitation spectra of ${ }^{26} \mathrm{Na}$ and ${ }^{25} \mathrm{Na}$ as mentioned in Fig. $2 \mathrm{~b}$ can be shown on top left plot of Fig. 3. Corresponding scattered deuterium kinetic energy plot would also prove that there was also a reaction of $\left(\mathrm{d}, \mathrm{d}^{\prime}\right)$ in the current experiment if selected. Furthermore, in Fig. $3 \mathrm{c}$ and $3 \mathrm{~d}$ for a specific state at $2.416 \mathrm{MeV}$ can be plotted for the $(\mathrm{d}, \mathrm{p})$ and $\left(\mathrm{d}, \mathrm{d}^{\prime}\right)$ reactions. This specific state was so apparent on the distinct black line in Fig $3 b$. These detections were possible due to the silicon detectors. An example of an angle gate in Fig 3c and $3 \mathrm{~d}$ can be seen here.

After checking on other reaction possibilities, a novel systematic method for searching new states and $\gamma$-rays in extensive cascades in the example of $(\mathrm{d}, \mathrm{p})$ reaction can be summarized in Fig. 4. The populated state at $2.225 \mathrm{MeV}$ in ${ }^{26} \mathrm{Na}$ was chosen as an illustration here. After zooming, the closely positioned states at $2.116 \mathrm{MeV}, 2.194 \mathrm{MeV}$ and $2.225 \mathrm{MeV}$ became more apparent in Fig. 4a. Among the three, $2.225 \mathrm{MeV}$ will be analyzed by using the gate limits as marked in the Fig. 4a.
This rectangle marking gives a hint about the background noise subtraction. The length and width of this rectangle also reflects the resolution of the particle and $\gamma$ detectors. Since the states adjacent to the state at $2.225 \mathrm{MeV}$ was obvious on its left side, the right side of the rectangle was a predictable $\gamma$-ray gate area for the background subtraction. Additionally, $\mathrm{Y}$ axis projection of this rectangle will give the $E_{\mathrm{ex}}$ limits in Fig. 4b. Then, we can check other linked $\gamma$-rays to the state at $2.225 \mathrm{MeV}$ by gating on this $\mathrm{E}_{\mathrm{ex}}$ limits. That worked nicely in the analysis.

Another method was to scan $\gamma$-ray spectra by $500 \mathrm{keV}$ of $\mathrm{E}_{\mathrm{ex}}$ intervals. In this method, the intensities of the observable $\gamma$-ray peaks will sometimes either fade away or to raise up as a hint. Thus, the systematic behavior of $\gamma$-ray peaks for specific $E_{\mathrm{ex}}$ ranges will be noticeable. From this information, the linked $\gamma$-rays could be traceable. For instance, both the Fig. $4 \mathrm{~b}$ and Fig. $4 \mathrm{~d}$ tell us some higher laying excitation energy region will also decay via 2.225 MeV state via $2225 \mathrm{keV} \gamma$-ray in its cascade. Later, this information turned to be true for the state at $4.305 \mathrm{MeV}$ in the analysis (Celik, 2014). To reverse the method for a double check, 

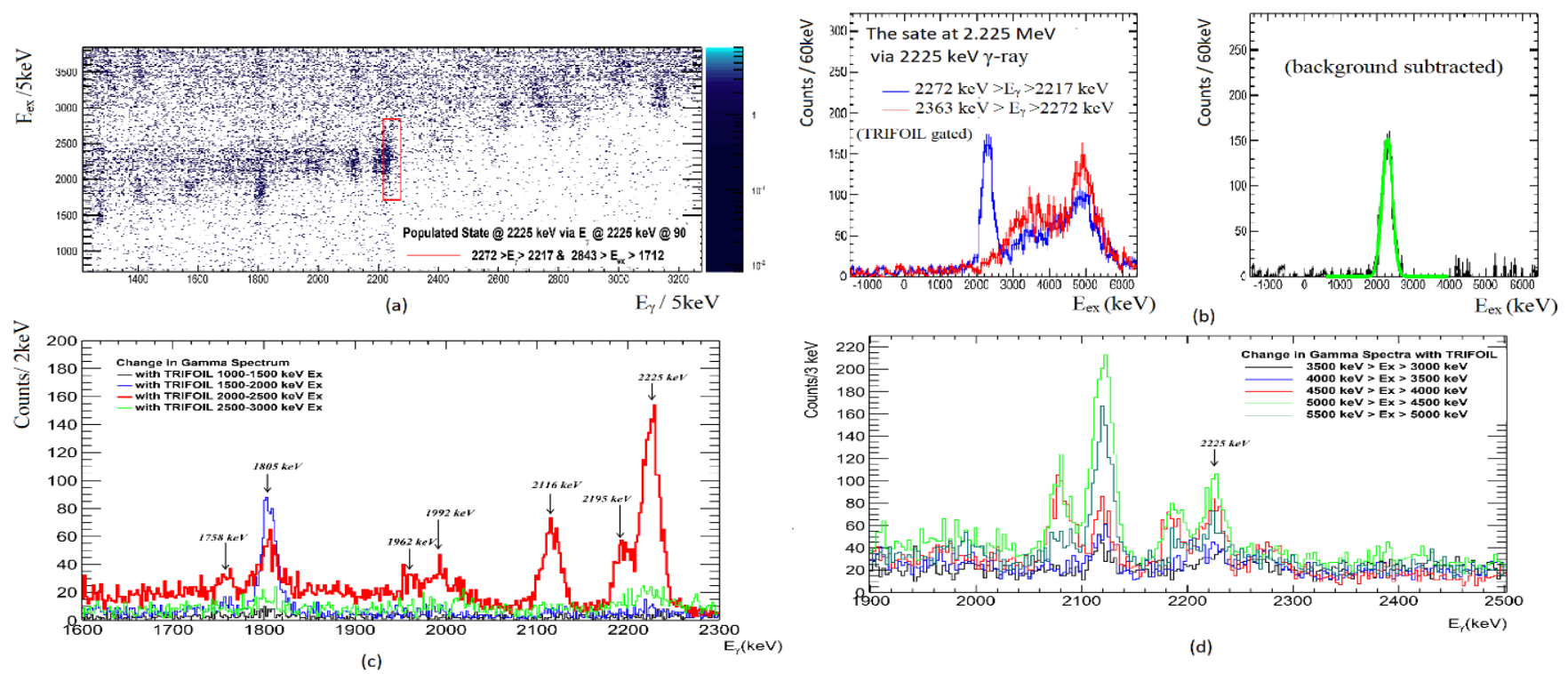

(d)

Figure 4: In Fig. a, the state at 2.225MeV was marked in $\mathrm{E}_{\mathrm{ex}}$ versus $\mathrm{E} \gamma$ plot for $26 \mathrm{Na}$ in the reaction of $25 \mathrm{Na}(\mathrm{d}, \mathrm{p} \gamma) 26 \mathrm{Na}$. This marked area was used to lead the investigation of $E_{e x}$ and E $\gamma$ spectra as seen in Fig b, c and d (Catford at al., 2015).

the limit range of a $\gamma$-ray peak at $2225 \mathrm{keV}$ as seen in Fig. 4c or the Fig. $4 \mathrm{~d}$ can be used initially as a gate to plot Eex spectrum in comparison to the Fig. 4b. They should be expected to be the same or similar in terms of limits. That also proved to be true in the analysis.

\section{Conclusions and Comments}

In conclusion, the different aspects of sample experiment and its set-up was mentioned here and used also in elsewhere (Celik at al., 2019a; Celik, 2019b) as a method. Emphasis was, this time, on the usage of both particle detector SHARC and $\gamma$-ray detector TIGRESS. It was proven that SHARC detector sought a help from high resolution TIGRESS detector due to its wide excitation energy resolution. With superior dissociation ability of $\gamma$-ray detectors, it was easier to work on overlapping peaks in the analysis. Analysis of this kind has mostly a great $\gamma$-ray level schemes as given in the article (Celik at al., 2019). To work out each level in such a $\gamma$-ray cascade, putting on small intervals of $E_{\text {ex }}$ gates on $\mathrm{E} \gamma$ spectra turned out to be the efficient way to see the behavior of $\gamma$-ray peaks for different $E_{\mathrm{ex}}$ regions. The combined power of both detector types enabled us to see, for instance, 26 experimentally observed states for this neutron transfer experiment as outlined in the article by Celik (Celik at al. 2019). In this study, it was intended to prove that the combination of particle- $\gamma$ information of any kind in the analysis was such a power tool in these aspects.

\section{Acknowledgement}

The SHARC project with code S1107 was funded by the UK Science and Technology Facilities Council and was led by Wilton Catford and Christian Diget from the Universities of Surrey and York in the UK. Thanks to you all for the past years.

\section{References}

AIP Conference Proceedings 150, 710 (1986); https:// doi.org/10.1063/1.36053, np reaction studies

Ball, G. C., Davies, W. G., Forster, J. S., \& Hardy, J. C. (1972). Use of the $\left({ }^{7} \mathrm{Li},{ }^{7} \mathrm{Be}\right)$ reaction to measure the mass of ${ }^{26} \mathrm{Na}$. Physical Review Letters, 28(16), 1069-1071. https://doi.org/10.1103/PhysRevLett.28.1497.4

Catford, W.N. at al. (2015). Structure of ${ }^{26} \mathrm{Na}$ via a novel technique using $(\mathrm{d}, \mathrm{p} \gamma)$ with a radioactive ${ }^{25} \mathrm{Na}$ beam. Acta Physica Polonica B, 46 https://doi.org/10.5506/APhysPolB.46.527

Celik, I. C. (2014). A particle- $\gamma$ coincidence study of ${ }^{26} \mathrm{Na}$ using the transfer reaction ${ }^{25} \mathrm{Na}(\mathrm{d}, \mathrm{p} \gamma)^{26} \mathrm{Na}$. (Ph.D thesis, University of Surrey, Guildford, 2014).

Celik, I.C., Catford, W.N., Matta, A., Wilson, G.L. (Nov. 25, 2019a). The extended energy regime of ${ }^{26} \mathrm{Na}$ via transfer reaction in inverse kinematics. AIP Conference Proceedings 2178, 030054. https://doi.org/10.1063/1.5135452

Celik, I.C. (Nov. 25, 2019b), "Gamma-ray angular distribution analysis of transfer reaction data for excited states of ${ }^{26} \mathrm{Na}$. AIP Conference Proceedings 2178, 030055. https://doi.org/10.1063/1.5135453

Firestone, R.B. (2009). Nuclear Data Sheets 110, p. 1691.

Flynn, E.R. \& Garret, J.D. ${ }^{26} \mathrm{Mg}\left(\mathrm{t},{ }^{3} \mathrm{He}\right)$ reaction and a sphericalshell-model description of ${ }^{26} \mathrm{Na}$. Phys. Rev. C, 9 (1), January (1974). https://doi.org/10.1103/PhysRevC.9.210

Jänecke, J. (1973, April, 16). The reaction ${ }^{26} \mathrm{Mg}(\mathrm{d}, \tau){ }^{25} \mathrm{Na}$ and the structure of ${ }^{25} \mathrm{Na}$. Nuclear Physics A, 204, 3, 497-515. https://doi.org/10.1016/0375-9474(73)90390-4

Krämer, E., Mairle, G. \& Kaschl, G. (1971, April, 13). Proton pickup from the magnesium isotopes: ${ }^{24,25,26} \mathrm{Mg}(\mathrm{d}, \mathrm{t})^{23,24,25} \mathrm{Na}$. Nuclear Physics A, 165, 2, 353-383. https://doi.org/10.1016/0375-9474(71)90765-2

Lee, S. at al. (2006). Structure of ${ }^{26} \mathrm{Na}$ from the ${ }^{14} \mathrm{C}\left({ }^{14} \mathrm{C}, \mathrm{d}\right)$ reaction. Physical Review C, 73(4). https://doi.org/10.1103/PhysRevC.73.044321 
Obertelli, A. at al. (2006). $\gamma$ spectroscopy of ${ }^{25,27} \mathrm{Ne}$ and ${ }^{26,27} \mathrm{Na}$.
Physical
Review
$\mathrm{C}$,
74(6).

https://doi.org/10.1103/PhysRevC.74.064305

Scott, D. K. at al. (1974). Spectroscopy of exotic nuclei using heavy-ion transfer reactions. Physical Review Letters, 33(22),1343-1346.

https://doi.org/10.1103/PhysRevLett.33.1343

Weissman L. at al. (2004, November, 19). Beta decay of ${ }^{26} \mathrm{Ne}$.
Phys.
Rev.
$\mathrm{C}$,
70 ,
057306 .

https://doi.org/10.1103/PhysRevC.70.057306

Wilson, G.L. (2012). Investigating the evolution of the nuclear magic numbers via single-neutron transfer populating ${ }^{26} \mathrm{Na}$. (Ph.D thesis, University of Surrey, Guildford, 2012). 